\title{
Chemical composition and bioactivity of methanolic extract obtained from Lepista sordida
}

\author{
Krishnendu Acharya $^{\oplus 1 *}$, Sandipta Ghosh ${ }^{11}$, Rhituparna Biswas ${ }^{1}$ \\ ${ }^{1}$ Molecular and Applied Mycology and Plant Pathology Laboratory, Department of Botany, \\ University of Calcutta, 35, Ballygunge Circular Road, West Bengal, India
}

\begin{abstract}
The present study aimed at the evaluation of chemical composition and bioactive potential of methanolic extract obtained from Lepista sordida in terms of antioxidative and antimicrobial efficacy. The macrofungus is recognized for its high nutritional value and medicinal properties. However, to the best of our knowledge bioactivity of its methanolic extract is yet to be explored. In this investigation, quantitative analysis of mycochemicals revealed the extract contained significant amount of phenolic compounds such as phenols and flavonoids. Ascorbic acid was found in higher amount than $\beta$ carotene and lycopene which were present in vestigial amounts. A phenolic profile was also determined using high performance liquid chromatography that further confirmed the presence of 10 phenolic constituents in the extract. Furthermore, the extract was subjected for determining antioxidant potential in different in-vitro assays. The findings showed remarkable 2, 2-Diphenyl-1-picrylhydrazyl and ABTS radical scavenging ability which was evident by low $\mathrm{EC}_{50}$ values, $330 \mu \mathrm{g} / \mathrm{mL}$ and $30 \mu \mathrm{g} / \mathrm{mL}$ respectively. The extract also demonstrated good chelating and reducing ability, an important marker of antioxidant compounds. Antimicrobial screening displayed positive results against Staphylococcus aureus and Escherichia coli. Altogether, the observations recommend therapeutic application of this mycotaxon on a commercial basis.
\end{abstract}

Keywords: Antimicrobial. Free radical scavenger. High performance liquid chromatography. Mycotaxon. Mycochemicals.

\section{INTRODUCTION}

From ancient past, mushrooms are widely consumed as a delicacy in many Asian and Western countries since they are enriched with high quality proteins, carbohydrates, fibers, minerals, vitamins and since they also possess delicious taste and flavor (Khatua et al., 2017). Recently, in $20^{\text {th }}$ century they are emerging as a potential candidate in the field of alternative medicine. Different groups of bioactive metabolites including polyphenolic compounds, terpenoids, tocopherols, $\beta$-glucan are known to be accumulated by this group of fungi that imparts unique therapeutic effects (Boonsong, Klaypradit, Wilaipun, 2016). Therefore they could be directly exploited for mankind due to their immense health promoting benefits as an antioxidant, anticancer, antidiabetic, immune-stimulatory agents.

\footnotetext{
*Correspondence: K. Acharya. Molecular and Applied Mycology and Plant Pathology Laboratory, Department of Botany, University of Calcutta, 35, Ballygunge Circular Road, Kolkata 700019, West Bengal, India. E-mail: krish_paper@yahoo.com
}

Medicinal mushrooms are one of the major sources of polyphenols and their derivatives and also recognized as a repository of antimicrobial metabolites (Shen et al., 2017). Literature study implicates phenolic compounds for being solely responsible for several protective effects against free radical induced injuries and microorganisms etc (Wong et al., 2009). Moreover, in recent times most of the synthetic drugs used in treatment of infectious diseases have gradually become ineffective due to nonselective application and harmful side effects. Thereby in present scenario, mushrooms with their reservoir of polyphenols and medicinally promising bio-compounds have drawn great attention from the scientific world with a promise that they could overcome the drawbacks of synthetic antioxidants and traditional antibiotic drugs.

L. sordida is such a mushroom that belongs to the clitocyboid agaric genus (Family-Tricholomataceae), commonly known as flesh-brown blewit. The species was first described by Mycologist Elias Magnus Fries as Agaricus sordidus (Thongbai et al., 2017). Widely distributed in Asia, North America and Europe, 8 species 
of Lepista genus have been recorded as edible from all over the world (Alvarado et al., 2015). Among them majority of the medicinal attributes have been assigned to $L$. sordida. A vast number of studies have been documented regarding its ideal condition of cultivation, especially of the Chinese and Thai strains (Tian, Feng, Zhong, 2003; Li et al., 2014, Thongbai et al., 2017). They are described as a rich source of carbohydrates, essential amino acids, dietary fibers (Hu et al., 2016). In addition, many bioactive metabolites namely diterpenoids (lepistal and lepistol), dioxygenated diketopiperazines, lepistamides A-C, diatretol were isolated from submerged mycelial cultures of the macrofungus (Mazur et al., 1996; Chen et al., 2011). Its water soluble polysaccharides have shown strong anticancer activity against laryngocarcinoma cells that signaled through $\mathrm{HMGB} 1 / \mathrm{NF}-\kappa \mathrm{B}$ pathway (Hu et al., 2016). Zhong et al. (2013) also demonstrated free radical scavenging and anti-aging effects of an intracellular polysaccharide isolated from submerged mycelial culture of this mushroom. Although there is no report regarding bioactive mycochemical content in methanolic extract of this taxon and free radical scavenging and bactericidal potentials of wild species. Therefore, in the present investigation, we highlight the phenolic profile of the methanolic extract of this mushroom and its concurrent bioactivity so that it will enhance its therapeutic value.

\section{MATERIAL AND METHODS}

\section{Chemicals}

Acetone, hexane, methanol, aluminum nitrate, sodium acetate, folin-cicolteau reagent, sodium carbonate, oxalic acid, DCPIP dye, ferric chloride, ferrous chloride, ferrozine, potassium ferricyanide, trichloroacetic acid (TCA), 2,2-diphenyl-1-picrylhydrazyl (DPPH), sodium sulfate, ammonium molybdate, 2,2'-Azino-bis(3ethylbenzothiazoline-6-sulfonic acid) (ABTS), potassium persulfate, ascorbic acid, ethylene diaminetetraacetic acid (EDTA), trolox, gallic acid, quercetin, nutrient broth (NB), dimethyl sulphoxide (DMSO), $p$-iodonitrotetrazolium chloride (INT) were purchased from Himedia, Mumbai, India.

\section{Test organisms}

Bacterial strains that were used as test organisms, Bacillus subtilis MTCC Code 736, Listeria monocytogenes MTCC Code 657, Staphylococcus aureus MTCC Code 96, Escherichia coli MTCC Code 68, Klebsiella pneumoniae MTCC Code 109 and Salmonella typhimurium MTCC
Code 98 were obtained from MTCC, Institute of Microbial Technology, Chandigarh, India. Bacteria were cultured in nutrient agar medium, aerobic condition at $37^{\circ} \mathrm{C}$. Before each experiment, subculturing of each strain was carried out in nutrient broth (NB).

\section{Instrument}

Bio-Rad iMarkTM Microplate Reader (USA) was used for absorbance measurement of 96 well plate. The instrument consists of an eight-channel, vertical path length photometer that reads at specific wavelengths such as $415,450,490,595,655$, and $750 \mathrm{~nm}$ in 96-well microtiter plate.

\section{Mushroom collection}

Fresh basidiocarps of wild $L$. sordida were collected from Gangetic plains of Murshidabad district of West Bengal. The mushroom was brought to the laboratory for identification and distinguishing micro-morphological features were documented consulting standard literature (Pegler, 1986). A voucher specimen was preserved in CUH herbarium with the accession number CUHAM165 following the protocol of Pradhan, Dutta, Acharya (2015). Fruiting bodies were dried at $40{ }^{\circ} \mathrm{C}$ overnight and then ground in a mixer grinder to obtain a fine powder which was stored in a fresh container for further use.

\section{Preparation of methanolic extract}

Dried powdered sample was extracted in methanol and after 24 hours solution was filtered through Whatman filter paper, again fresh solvent was added for re-extraction. Final filtrate obtained was kept at $4{ }^{\circ} \mathrm{C}$ for further use. Organoleptic characters of the extract were recorded.

\section{Mycochemicals estimation}

Freshly prepared methanolic extract was subjected for quantification of phytochemicals. Total phenol content was estimated using Folin-ciocalteu reagent, gallic acid as standard (Singleton, Rossi, 1965). Flavonoid content was measured using Quercetin $(5-20 \mu \mathrm{g} / \mathrm{mL})$ as standard (Adebayo et al., 2012). Result was expressed as $\mu \mathrm{g}$ of quercetin equivalents per mg of extract. Ascorbic acid content was determined by titration against 2 , 6-dichlorophenol indophenol dye (Acharya et al., 2015). $\beta$-carotene and lycopene contents were estimated as per our previously published protocol (Acharya et al., 2016). 


\section{HPLC of methanol soluble extract}

The methanolic extract was filtered through $0.2 \mu \mathrm{m}$ filter and $20 \mu \mathrm{L}$ of the filtrate was loaded in the HPLC system (Agilent, USA). Separation was done on an Agilent Eclipse Plus C18 column (100 $\mathrm{mm} \times 4.6 \mathrm{~mm}, 3.5 \mu \mathrm{m})$ using a flow rate of $0.8 \mathrm{~mL} / \mathrm{min}$ at $25^{\circ} \mathrm{C}$. The mobile phase consisted of eluent A (acetonitrile) and eluent B (aqueous phosphoric acid solution, $0.1 \% \mathrm{v} / \mathrm{v}$ ). A gradient program was used for elution: $0-2 \mathrm{~min}, 5 \% \mathrm{~A} ; 2-5 \mathrm{~min}, 15 \% \mathrm{~A}$; 5-10 min, 40\% A; 10-15 min, 60\% A; 15-18 min, 90\% $\mathrm{A}$ and absorbance of sample solution was measured at $278 \mathrm{~nm}$ (Acharya, Mukherjee, Mitra, 2015).

\section{Antimicrobial assay}

Antimicrobial activity of the extract was determined by microdilution method (Stojković et al., 2013). Freshly prepared inoculi of six bacteria were seeded in a 96 well plate at a concentration of $1 \times 10^{5} \mathrm{CFU} / \mathrm{mL}$. Reaction mixture consisted of $200 \mu \mathrm{L}$ of NB, different concentrations of extracts $(50-500 \mu \mathrm{g} / \mathrm{mL})$ and $20 \mu \mathrm{L}$ inoculum. Positive and negative control was prepared by inoculated growth medium without adding test samples and DMSO respectively. Streptomycin was used as standard. Plate was incubated for 24 hours at $37^{\circ} \mathrm{C}$ followed by addition of $40 \mu \mathrm{L}$ of INT dye $(0.2 \mathrm{mg} / \mathrm{mL})$ in each well and further incubation for 30 minutes. $\mathrm{IC}_{50}$ value was calculated that indicates the concentration at which $50 \%$ bacterial growth was inhibited and compared against standard, Streptomycin.

\section{Antioxidant assays}

\section{DPPH radical scavenging assay}

DPPH scavenging potentiality of extracts was evaluated by using $0.004 \%$ DPPH in methanol solution and different concentrations of extracts (100-500 $\mu \mathrm{g} /$ $\mathrm{mL}$ ) following the protocol of Khatua, Ghosh, Acharya (2017). The reaction mixture was incubated for 30 minutes followed by measuring the absorbance at $595 \mathrm{~nm}$ in microplate reader. Scavenging activity was represented as percentage of inhibition with respect to ascorbic acid standard. $\mathrm{EC}_{50}$ values were calculated with the help of calibration curve indicating the concentration where 50\% DPPH radicals were scavenged. Percentage of scavenging activity was measured using the following formula:

Scavenging percentage (\%): $\left[\mathrm{A}_{\mathrm{DPPH}}-\mathrm{A}_{\mathrm{S}}\right] / \mathrm{A}_{\mathrm{DPPH}} \times 100$.

$\mathrm{A}_{\mathrm{DPPH}}$ is the absorbance of DPPH solution and $\mathrm{A}_{\mathrm{S}}$ is the absorbance of the solution containing various concentrations of extract.

\section{Chelating ability of ferrous ions}

For determination of ferrous ion $\left(\mathrm{Fe}^{2+}\right)$ chelating ability of the extracts, a standard protocol was followed (Khatua, Ghosh, Acharya, 2017). $200 \mu \mathrm{L}$ reaction mixtures comprised of $3 \mathrm{nM} \mathrm{FeCl}_{2}(5 \mu \mathrm{L})$ and different concentrations of extract were prepared separately in a 96 well plate $(50-300 \mu \mathrm{g} / \mathrm{mL})$. Reaction was commenced after addition of $0.12 \mathrm{nM}$ ferrozine $(10 \mu \mathrm{L})$ and after $10 \mathrm{~min}$ incubation; absorbance was measured at $595 \mathrm{~nm}$ using microplate reader. $\mathrm{EC}_{50}$ values were calculated from graph plotted against EDTA as standard. Results were represented as percentage of suppression of $\mathrm{Fe}^{2+}$-Ferrozine complex formation.

\section{Reducing power assay}

Additionally, reducing power of the methanolic extract was examined using the following procedures (Khatua, Ghosh, Acharya, 2017). $10 \mu \mathrm{L}$ of different concentrations of extracts $(60-220 \mu \mathrm{g} / \mathrm{mL})$ along with respective amounts of water and $0.2 \mathrm{M} \mathrm{Na}$-phosphate buffer, $\mathrm{pH} 6.6(25 \mu \mathrm{L})$ were mixed with freshly prepared $1 \%$ potassium ferricyanide solution $(25 \mu \mathrm{L})$ and incubated for 20 minutes at room temperature. After that, $85 \mu \mathrm{L}$ water and $8.5 \mu \mathrm{L}$ ferric chloride were added in each well separately. Finally, the optical density was determined at $750 \mathrm{~nm}$ using same microplate reader as mentioned earlier. Ascorbic acid was used as standard and $\mathrm{EC}_{50}$ value was evaluated at the concentration exhibiting 0.5 absorbance value.

\section{ABTS radical scavenging assay}

ABTS radical scavenging activity of the methanolic extract was estimated spectophotometrically following the method of Khatua, Ghosh, Acharya (2017). ABTS $^{\circ+}$ radical was formed by mixing equal proportion of $7 \mathrm{mM} \mathrm{ABTS}$ dissolved in water with $2.45 \mathrm{mM}$ potassium persulfate and then the mixture was kept for 12-16 hours in dark condition at room temperature. Before use, dilution of ABTS + solution was executed to get an absorbance of 0.700 at $750 \mathrm{~nm}$. Reaction sets $(200 \mu \mathrm{L})$ were prepared for various concentrations of extract $(10-50 \mu \mathrm{g} / \mathrm{mL})$ and Trolox, a positive control followed by 10 minutes incubation. After incubation absorbance was taken at $750 \mathrm{~nm}$. Percentage of ABTS + radical scavenging activity was calculated and $\mathrm{EC}_{50}$ was determined from calibration curve.

\section{Total antioxidant activity}

Total antioxidant activity of the extract was determined as reported by Prieto, Pineda, Aguilar (1999). 
$3.3 \mathrm{~mL}$ reaction mixture contained of $0.3 \mathrm{~mL}$ sample solution and $3 \mathrm{~mL}$ freshly prepared reagent solution comprising of $0.6 \mathrm{M}$ sulphuric acid, $28 \mathrm{mM}$ sodium sulphate and $4 \mathrm{mM}$ ammonium molybdate. Tubes were incubated at $95{ }^{\circ} \mathrm{C}$ for 90 minutes and after cooling down absorbance were measured at $695 \mathrm{~nm}$ against blank. Ascorbic acid (1-30 $\mu \mathrm{g} / \mathrm{mL})$ was used to prepare standard curve and values were expressed as the number of equivalents of ascorbic acid.

\section{Statistical analysis}

Herein, all results are represented as mean \pm standard deviation of three independent experiments each in triplicates and statistically evaluated using Microsoft ${ }^{\circledR}$ Office Excel (Microsoft ${ }^{\circledR}$, USA).

\section{RESULTS AND DISCUSSION}

\section{Mycochemical composition}

Literature studies validated the most effective solvent for extraction of phytochemicals from mushroom is the polar solvent mainly methanol and its extractive yield is also higher compared to other polar solvents (Padalia, Chanda, 2015). Herein methanol is used to extract and quantify mycochemicals present in fruiting bodies of $L$. sordida. The methanolic extract was brown coloured, with an extractive value of $7.8 \%$. Freshly prepared fraction was subjected for quantification of bioactive mycochemicals using standard protocols. Total phenol content was estimated at $17.1 \pm 0.14 \mu$ g gallic acid equivalent/mg of extract. The extract contained flavonoid accounting for $0.125 \pm 0.28 \mu \mathrm{g}$ quercetin equivalent/ $\mathrm{mg}$ of extract. Ascorbic acid was also present in notable amount i.e. $2.083 \pm 1.08 \mu \mathrm{g} / \mathrm{mg}$ of extract. $\beta$-Carotene and lycopene were found in little amounts $(0.052 \pm 0.04 \mu \mathrm{g} / \mathrm{mg}$ and $0.045 \pm 0.01 \mu \mathrm{g} / \mathrm{mg}$ of the extract respectively). However, our results indicated this methanolic fraction of L. sordida is more enriched with secondary metabolites than methanol extract of Schizophyllum commune (Acharya, Ghosh, Dutta, 2016), Lentinula edodes (Acharya, Mukherjee, Mitra, 2015) as well as Polyphenolrich extract of Pleurotus flabellatus (Dasgupta, Sherpa, Acharya, 2014).

\section{Chromatographic fingerprinting}

Furthermore, HPLC profile of the extract was recorded that served as a phenolic fingerprint of the fraction. Chromatogram analysis revealed at least 20 components are present excluding solvent peaks (Figure 1) after scanning at $278 \mathrm{~nm}$. Retention times and respective areas of each peak are given in Table I.

\section{Antimicrobial activity}

Due to emergence of antibiotic resistant microbial flora, most of the commercially available antibiotic drugs exploited in treatment of several microbial diseases become ineffective (Ventola, 2015). Searching for alternative drugs of natural sources is of utmost need to combat this crisis. The present investigation showed that the methanol extract of $L$. sordida was an efficient antibacterial agent against $S$. aureus, a Gram positive bacterium, although it did not show any effects against $K$. pneumonieae even after high dose treatment. With respect to Table II, Gram positive bacteria including S. aureus, L. monocytogenes and B. subtilis were more susceptible to the extract as indicated by low $\mathrm{IC}_{50}$ values than Gram negative ones. The result is consistent with diterpenoid lepistal activity as reported by Mazur et al. (1996).

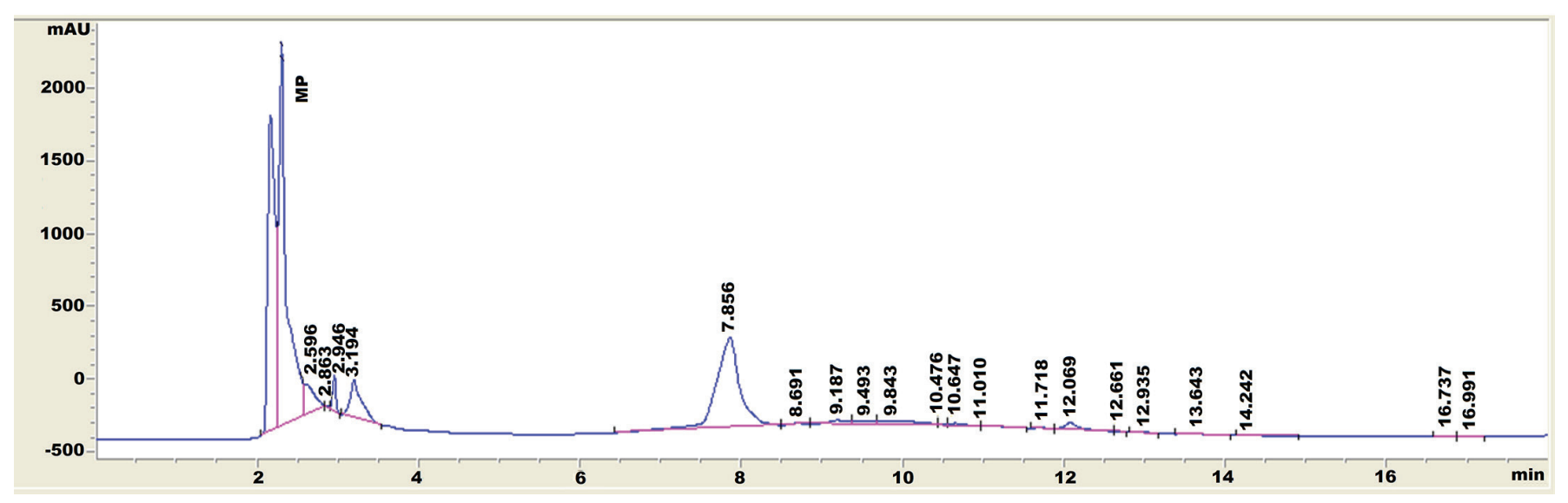

FIGURE 1 - Enlarged HPLC chromatogram of methanolic fraction obtained from Lepista sordida. 
TABLE I - HPLC profile of methanolic fraction obtained from Lepista sordida

\begin{tabular}{lcc}
\hline Peak number & $\begin{array}{c}\text { Retention time } \\
(\mathbf{m i n})\end{array}$ & Area (AU) \\
\hline $\mathbf{1}$ & 2.596 & 1714.413 \\
$\mathbf{2}$ & 2.863 & 56.859 \\
$\mathbf{3}$ & 2.946 & 736.710 \\
$\mathbf{4}$ & 3.194 & 2566.952 \\
$\mathbf{5}$ & 7.856 & 1.273 \\
$\mathbf{6}$ & 8.691 & 113.827 \\
$\mathbf{7}$ & 9.187 & 533.060 \\
$\mathbf{8}$ & 9.493 & 506.852 \\
$\mathbf{9}$ & 9.843 & 1050.524 \\
$\mathbf{1 0}$ & 10.476 & 108.999 \\
$\mathbf{1 1}$ & 10.647 & 214.414 \\
$\mathbf{1 2}$ & 11.010 & 63.285 \\
$\mathbf{1 3}$ & 11.718 & 58.162 \\
$\mathbf{1 4}$ & 12.069 & 601.199 \\
$\mathbf{1 5}$ & 12.661 & 15.939 \\
$\mathbf{1 6}$ & 12.935 & 80.007 \\
$\mathbf{1 7}$ & 13.643 & 100.456 \\
$\mathbf{1 8}$ & 14.242 & 49.006 \\
$\mathbf{1 9}$ & 16.737 & 13.838 \\
$\mathbf{2 0}$ & 16.991 & 14.679 \\
\hline
\end{tabular}

\section{Antioxidant assay}

For determination of antioxidative potentiality of any compounds, one single assay would not be able to confirm accurately an agent's true potential basically for the fact that antioxidant activity entails multiple processes such as reactive radical scavenging, metal chelation, reducing power etc. Therefore in the present investigation, five different in vitro assays were performed to evaluate antioxidative efficacy of $L$. sordida.
DPPH; an organic commercially accessible free radical was utilized as a simple method of screening of free radical scavenging potentiality of test compounds. Antioxidant molecules can effectively scavenge DPPH radical that visibly reflects to the discoloration of violet coloured DPPH solution. Therefore, the more rapidly the colour changes, the more powerful the free radical scavenging activity of the extract. In the present study, methanolic extract of $L$. sordida exhibited excellent scavenging activity that increased upto $71.63 \%$ at the higher doses of $500 \mu \mathrm{g} / \mathrm{mL}$ (Figure 2). $\mathrm{EC}_{50}$ value has been presented in Table III, andit depicts methanolic extract of L. sordida as a strong antioxidative fraction in comparison with methanolic extract of L. sordida $\left(\mathrm{EC}_{50} 9.82 \mathrm{mg} / \mathrm{mL}\right)$ (Heleno et al., 2010) and ethanolic extract of Entoloma lividoalbum $\left(\mathrm{EC}_{50} 2.13 \mathrm{mg} / \mathrm{mL}\right.$ ) (Dasgupta, Rai, Acharya, $2015)$ and Macrocybe crassa $\left(\mathrm{EC}_{50} 1.66 \mathrm{mg} / \mathrm{mL}\right.$ ) (Khatua, Acharya, 2014).

Furthermore, chelating capacity of the extract was determined by ferrozine assay. The principle is based on interruption of ferrous ion-ferrozine complex production by antioxidant compounds which chelate ferrous ions thus inhibiting free radical generation. In the present study, the methanolic extract demonstrated good chelating activity as the violet coloured complex was maximally inhibited at the highest concentration of the extract $(300 \mu \mathrm{g} / \mathrm{mL})$. Figure 2 depicts that at concentrations of 70,100 and $300 \mu \mathrm{g} / \mathrm{mL}$, the fraction exhibited remarkable chelating activity at the rate of $19.47 \%, 49.8 \%$ and $74.03 \%$ respectively. In our previous publication, chelating ability of ethanolic extract from Termitomyces clypeatus had been recorded (Mitra et al., 2016) which exhibited higher $\mathrm{EC}_{50}$ value of $0.21 \mathrm{mg} / \mathrm{mL}$ compared to $L$. sordida $\left(\mathrm{EC}_{50}\right.$ $177 \pm 1.25 \mu \mathrm{g} / \mathrm{mL})$.

Reducing power is usually categorized as an indicator of antioxidative efficacy of test compounds. It depends on electron donating capacity of compounds that reduce $\mathrm{Fe}^{3+}$ /ferricyanide complex to $\mathrm{Fe}^{2+}$ form (Boonsong, Klaypradit, Wilaipun, 2016). Yellow colored reaction

TABLE II - Antimicrobial activity of methanolic fraction extracted from Lepista sordida. Results are represented as $\mathrm{IC}_{50}$ value (mean \pm standard deviation; $\mathrm{n}=3$ )

\begin{tabular}{lccc}
\hline Bacterial types & Bacterial strains & $\mathbf{I C}_{\mathbf{5 0}}$ value $(\boldsymbol{\mu g} / \mathbf{m L})$ & Streptomycin $(\boldsymbol{\mu g} / \mathbf{m L})$ \\
\hline \multirow{3}{*}{ Gram positive } & a) Bacillus subtilis & 535.76 & 5.608 \\
& b) Listeria monocytogenes & 288.95 & 4.68 \\
& c) Staphylococcus aureus & 30.6 & 6.295 \\
\hline \multirow{3}{*}{ Gram negative } & a) Escherichia coli & 90 & 5.415 \\
& b) Salmonella typhimurium & 658.83 & 5.092 \\
& c) Klebsiella pneumonieae & Nil & 5.294 \\
\hline
\end{tabular}


mixture gradually changes to various shades of green colour denoting reducing ability of test sample as the concentration of sample increases. Figure 2 shows that reducing capacity of the methanolic extract had a strong dose dependent increment, maximum at $220 \mu \mathrm{g} / \mathrm{mL}$ (absorbance-0.62). However the sample exhibited better activity $\left(\mathrm{EC}_{50} 160 \pm 0.89 \mu \mathrm{g} / \mathrm{mL}\right)$ than methanolic extract of Pleurotus sajor-caju $\left(\mathrm{EC}_{50} 1.31 \mathrm{mg} / \mathrm{mL}\right)$ and P. sapidus $\left(\mathrm{EC}_{50} 2.53 \mathrm{mg} / \mathrm{mL}\right)$ (Jeena et al., 2014).

ABTS radical scavenging assay was performed which is considered as one of the time-saving simple technique to determine free radical scavenging potentials of natural compounds. In this method, directly produced blue-green $\mathrm{ABTS}^{\cdot+}$ radical is reduced to its natural colorless form in presence of antioxidant molecules (Islam, Yu, Xu, 2016). Herein, the methanolic extract of L. sordida possessed a remarkable scavenging activity which gradually increased from $29.73 \%$ to $65.47 \%$ at $20 \mu \mathrm{g} / \mathrm{mL}$ and $40 \mu \mathrm{g} / \mathrm{mL}$ concentrations respectively
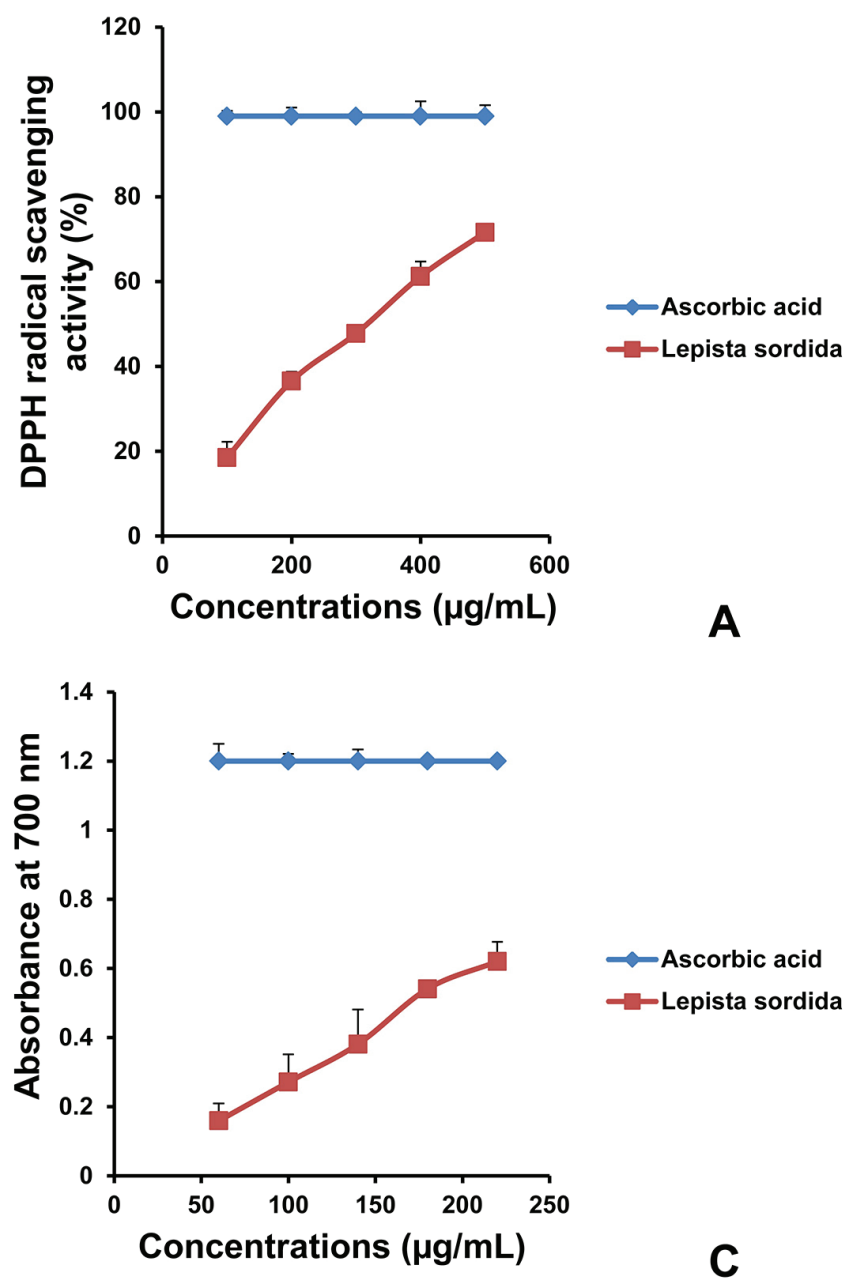

(Figure 2). $\mathrm{EC}_{50}$ value was found to be comparatively lower indicating strong scavenging activity than methanolic extract of Pleurotus ostreatus $\left(\mathrm{EC}_{50} 76.63 \mathrm{mg} / \mathrm{mL}\right)$ as reported by González-Palma et al. (2016).

Finally, total antioxidant capacity was measured using Phosphomolybdenum method and the value was compared with natural antioxidant ascorbic acid. Results showed that $1 \mathrm{mg}$ of extract was equivalent to $36.25 \mu \mathrm{g}$ of ascorbic acid.

\section{CONCLUSION}

The present study reveals that the methanolic extract of $L$. sordida has an excellent free radical scavenging potency which may correlate with the presence of significant amount of antioxidant compounds such as phenols, flavonoids and ascorbic acid. However, HPLC data served as phenolic fingerprint of this mushroom and confirmed the bioactive properties of the extract. Thus
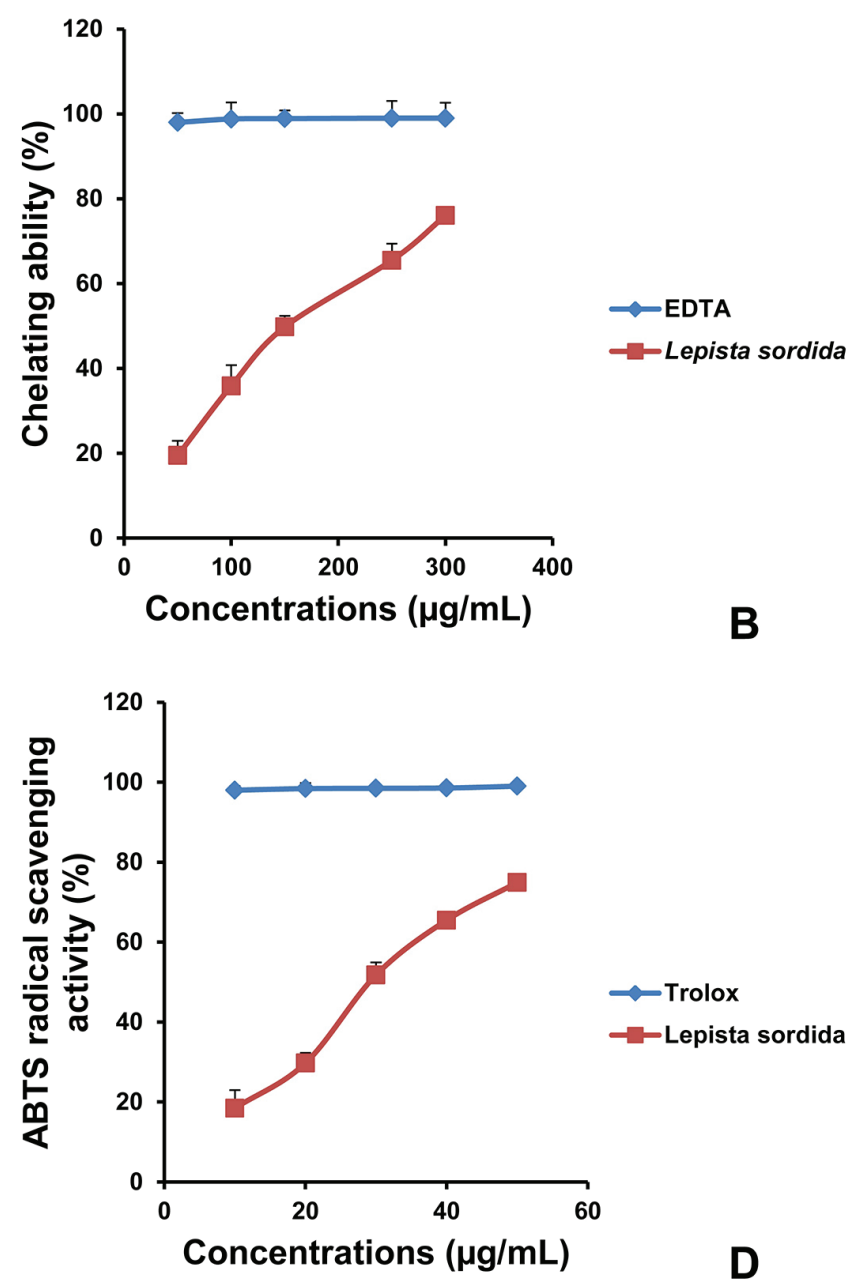

FIGURE 2 - Antioxidant activity of methanolic extract from Lepista sordida A) DPPH radical scavenging activity B) Chelating ability C) Reducing power D) ABTS radical scavenging activity. 
TABLE III - Antioxidant activity of methanolic fraction extracted from Lepista sordida. Results are expressed in EC50 values (mean \pm standard deviations; $\mathrm{n}=3$ )

\begin{tabular}{lcc}
\hline Antioxidant assays & Methanolic extract $(\boldsymbol{\mu g} \mathbf{m} \mathbf{m L})$ & Standard $(\boldsymbol{\mu g} / \mathbf{m L})$ \\
\hline DPPH radical scavenging activity & $330 \pm 0.23$ & $7.69 \pm 0.03$ \\
Chelating ability of ferrous ion & $177 \pm 1.25$ & $11.81 \pm 0.02$ \\
Reducing power & $160 \pm 0.89$ & $18.74 \pm 0.01$ \\
ABTS radical scavenging activity & $30 \pm 2.29$ & $3.18 \pm 0.01$ \\
\hline
\end{tabular}

the investigation will help to exploit this mushroom as an alternative resource of natural antioxidants to synthetic ones such as BHA, BHT etc that possess harmful effects on human health. Moreover, the extract was also effective against tested gram negative and gram positive bacteria indicating its possible application as potential source of antibiotics.

\section{ACKNOWLEDGEMENT}

Authors are thankful to DST, FIST, Government of India for providing financial support for departmental instrumental facilities.

\section{REFERENCES}

Acharya K, Bera M, Tarafder E, Dasgupta A. Pharmacognostic standardization of Ganoderma lucidum: A commercially explored medicinal mushroom. Der Pharm Lett. 2015;7(7):175181

Acharya K, Ghosh S, Dutta AK. Pharmacognostic standardization based on physicochemical and molecular parameters of a medicinal mushroom Schizophyllum commune. Orient Pharm Exp Med. 2016;16(4):259-266.

Acharya K, Ghosh S, Khatua S, Mitra P. Pharmacognostic standardization and antioxidant capacity of an edible mushroom Laetiporus sulphureus. J Verbr Lebensm. 2016;11(1):33-42.

Acharya K, Mukherjee S, Mitra P. Pharmacognostic standardisation of Lentinula edodes: A widely explored medicinal mushroom. Int J Pharmacog Phytochem Res. 2015;7(4):866-872.

Adebayo EA, Oloke JK, Ayandele AA, Adegunlola CO. Phytochemical, antioxidant and antimicrobial assay of mushroom metabolite from Pleurotus pulmonarius-LAU 09 (JF736658). J Microbiol Biotech Res. 2012;2(2):366-374.
Alvarado P, Moreno G, Vizzini A, Consiglio G, Manjón JL, Setti L. Atractosporocybe, Leucocybe and Rhizocybe: three new clitocyboid genera in the tricholomatoid clade (Agaricales) with notes on Clitocybe and Lepista. Mycologia. 2015;107(1):123136.

Boonsong S, Klaypradit W, Wilaipun P. Antioxidant activities of extracts from five edible mushrooms using different extractants. Agric J Nat Resour. 2016;50(2):89-97.

Chen X-L, Wu M, Ti H-H, Wei X-Y, Li T-H. Three new 3,6-Dioxygenated Diketopiperazines from the basidiomycete Lepista sordida. Helv Chimica Acta. 2011;94(8):1426-1430.

Dasgupta A, Rai M, Acharya K. Phytochemical analysis and in vitro antioxidant activity of a wild edible mushroom Entoloma lividoalbum. Asian J Pharm Clin Res. 2015;8(5):171-174.

Dasgupta A, Sherpa AR, Acharya K. Phytochemical screening and antioxidant capacity of polyphenolrich fraction of Pleurotus flabellatus. J Chem Pharm Res. 201;6(5):1059-1065.

González-Palma I, Escalona-Buendía HB, Ponce-Alquicira E, Téllez-Téllez M, Gupta VK, Díaz-Godínez G, et al. Evaluation of the antioxidant activity of aqueous and methanol extracts of Pleurotus ostreatus in different growth stages. Front Microbiol. 2016;7:1-9.

Heleno SA, Barros L, Sousa MJ, Martins A, Ferreira ICFR. Tocopherols composition of Portuguese wild mushrooms with antioxidant capacity. Food Chem. 2010;119(4):1443-1450.

$\mathrm{Hu}$ W, Lin J, Su L, Liu M. LSPb1 inhibits the proliferation of laryngeal squamous cell cancer and neonatal vessels via HMGB1/NF-B pathway. Int J Clin Exp Med. 2016;9(11):2145821465 .

Islam T, Yu X, Xu B. Phenolic profiles, antioxidant capacities and metal chelating ability of edible mushrooms commonly consumed in China. LWT - Food Sci Technol. 2016;72:423-431. 
Jeena GS, Punetha H, Prakash O, Chandra M, Kushwaha KPS. Study on in vitro antioxidant potential of some cultivated Pleurotus species (Oyster mushroom). Indian J Nat Prod Resour. 2014;5(1):56-61.

Khatua S, Acharya K. Antioxidant and antimicrobial potentiality of quantitatively analysed ethanol extract from Macrocybe crassa. Int J Pharm Sci Rev Res. 2014;29(2):53-60.

Khatua S, Dutta AK, Chandra S, Paloi S, Das K, Acharya $\mathrm{K}$. Introducing a novel mushroom from mycophagy community with emphasis on biomedical potency. PLoS One. 2017;12(5):e0178050.

Khatua S, Ghosh S, Acharya K. A simplified method for microtiter based analysis of in vitro antioxidant activity. Asian J Pharmacol. 2017;11(2):S327-S335.

Li WS, Lue YS, Wu TY, Tsai SJ, Chen MH. Domestication of native Lepista soridida (Fr.) Singer in Taiwan. J Taiwan Agric Res. 2014;63(3):216-224.

Mazur X, Becker U, Anke T, Sterner O. Two new bioactive diterpenes from Lepista sordida. Phytochemistry. 1996;43(2):405-407.

Mitra P, Mandal NC, Roy A, Acharya K. Phytochemical study and antioxidative property of ethanolic extract from Termitomyces clypeatus. J Appl Pharm Sci. 2016;6(07):120-124.

Padalia H, Chanda S. Antimicrobial efficacy of different solvent extracts of Tagetes erecta L. flower, alone and in combination with antibiotics. Appl Micro Open Access. (2015);1:1000106.

Pegler DN. Agaric flora of Sri Lanka. Kew Bulletin Additional Series XII: Royal Botanic Gardens; Kew; 1986.

Pradhan P, Dutta AK, Acharya K. A low cost long term preservation of macromycetes for fungarium. Protoc Exch. 2015; doi:10.1038/protex.2015.026.
Prieto P, Pineda M, Aguilar M. Spectrophotometric quantitation of antioxidant capacity through the formation of phosphomolybdenum complex: specific application to the determination of vitamin E. Anal Biochem. 1999;269(2):334337.

Shen H-S, Shao S, Chen J-C, Zhou T. Antimicrobials from mushrooms for assuring food safety. Compr Rev Food Sci Food Saf. 2017;16(2):316-326

Singleton VL, Rossi JJ. Colorimetry of total phenolics with phosphomolybdic- phosphotungstic acid reagents. Am J Enol Viticult. 1965;16:144-158.

Stojković D, Reis FS, Ferreira ICFR, Barros L, Glamočlija $\mathrm{J}$, Ćirić A, et al. Tirmania pinoyi: Chemical composition, in vitro antioxidant and antibacterial activities and in situ control of Staphylococcus aureus in chicken soup. Food Res Int. 2013;53(1):56-62.

Thongbai B, Wittstein K, Richter C, Miller SL, Hyde KD, Thongklang N, et al. Successful cultivation of a valuable wild strain of Lepista sordida from Thailand. Mycol Progress. 2017;16(4):311-323.

Tian GT, Feng YQ, Zhong XX. A study on the domestication cultivation of Lepista sordida. Acta Edulis Fungi. 2003;10:5256.

Ventola CL. The antibiotic resistance crisis Part 1: Causes and Threats. Pharm Ther. 2015;40(4):277-283.

Wong KH, Vikineswary S, Noorlidah A, Umah RK, Murali N. Effects of cultivation techniques and processing on antimicrobial and antioxidant Activities of Hericium erinaceus (Bull. :Fr.) Pers. Ext Food Tech Biot. 2009;47(1):47-55.

Zhong W, Liu N, Xie Y, Zhao Y, Song X, Zhong W. Antioxidant and anti-aging activities of mycelial polysaccharides from Lepista sordida. Int J Biol Macromol. 2013;60:355-359.

Received for publication on $13^{\text {th }}$ December 2017 Accepted for publication on $21^{\text {st }}$ June 2018 